\title{
Motorcycle-related Trauma in the Philippines Resulting in Hospital Admission: the Epidemiology of Cases at the Philippine General Hospital
}

\author{
Rafael J. Consunji, ${ }^{1,2,3}$ Allan Joseph L. Larona, ${ }^{2,4}$ Ambrosio C. Jumangit, III ${ }^{2}$ and Shanthi N. Ameratunga ${ }^{5}$ \\ ${ }^{1}$ Division of Trauma, Department of Surgery, College of Medicine and Philippine General Hospital, University of the Philippines Manila \\ ${ }^{2}$ Study Group on Injury Prevention and Control, National Institutes of Health, University of the Philippines Manila \\ ${ }^{3}$ Trauma Surgery Section, Department of Surgery, Hamad General Hospital, Hamad Medical Corporation, Doha, Qatar \\ ${ }^{4}$ Department of Ophthalmology and Visual Sciences, College of Medicine and Philippine General Hospital, University of the Philippines Manila \\ ${ }^{5}$ School of Population Health, Faculty of Medical and Health Sciences at University of Auckland School of Population Health, Auckland, New Zealand
}

\begin{abstract}
Objective. To describe the epidemiology of motorcycle related trauma (MCRT) admitted to the Philippine General Hospital (PGH).

Method. Retrospective analysis of records of motorcycle crash victims admitted to the Trauma Division, Department of Surgery, PGH from January 1, 2004 to December 31, 2006.

Results. MCRT victims comprised $6.7 \%$ of all trauma admissions to PGH. Most were males (83.8\%) and young adults (median age 26 years), and $38.6 \%$ were road users other than motorcycle drivers or passengers (primarily pedestrians). Two-thirds of victims suffered multiple injuries (68.9\%). Common injuries were maxillo-facial (78\%), fractures of the lower and upper extremities (46.9\% and $36.1 \%$, respectively) and traumatic brain injuries $(40.7 \%)$. The median length of hospital stay was 13 days. The inhospital mortality rate was $5.8 \%, 43 \%$ of fatalities were due to traumatic brain injuries. Based on self-reported information, $88 \%$ of the motorcyclist victims were riding under the influence of alcohol, and $13 \%$ were wearing helmets at the time of the crash.
\end{abstract}

Conclusions. A significant proportion of MCRT victims are not motorcycle users. There is an urgent need to implement effective strategies to prevent MCRT in the Philippines, including the implementation and enforcement of national laws against drink driving and use of standard helmets.

Key Words: motorcycle crash, alcohol-related injury, motorcycle helmets, maxillo-facial trauma, traumatic brain injury

Presented at the 2nd Asia Pacific Conference on Injury Prevention, November 2008, Hanoi, Vietnam.

Poster presented at the 9th World Conference on Injury Prevention and Safety Promotion, March 2008, Merida, Mexico.

Paper won The Best Free Paper Award at the Southwest Area Network (SWAN) Trauma Conference XVIII, July 31, 2010, Liverpool Hospital, Sydney, Australia.

Corresponding author: Rafael J. Consunji MD, MPH

Trauma Surgery Section

Department of Surgery

Hamad General Hospital

Hamad Medical Corporation

Doha, Qatar 3050

Telephone: +974-4439-6842

Email: RConsunji@hmc.org.qa / uppgh_sicu@yahoo.com

\section{Introduction}

As noted in the 2004 World Report, ${ }^{1}$ approximately 1.2 million people die from motor vehicle crashes globally each year. The majority of these deaths occur in low and middle income countries, with pedestrians and motorcyclists being among the most vulnerable road crash victims. In addition to deaths, up to 50 million people worldwide are injured or permanently disabled in road crashes, annually. Among the 10 countries of the Association of Southeast Asian Nations (ASEAN) region (Brunei, Cambodia, Indonesia, Laos, Malaysia, Myanmar, the Philippines, Singapore, Thailand and Vietnam), 75,000 people die and 4.7 million are injured yearly in motor vehicle crashes with $12 \%(9,000)$ of the deaths and $10.5 \%(493,500)$ of the injuries estimated to occur in the Philippines. ${ }^{16}$ Economic losses from motor vehicle crashes are estimated to amount to $2.6 \%$ of the Philippine Gross Domestic Product (GDP) or USD\$1.9 billion annually. ${ }^{2}$

Pedestrian trauma is reported to account for greater than $70 \%$ of all severe road traffic injuries in the Philippines with motorcycle-related trauma (MCRT) comprising less than $10 \%$ of all victims. ${ }^{3}$ However, the distribution of road victim categories is expected to change with the substantial increase in the ownership of two- and three-wheeled motorcycles in the country. Motorcycle registration in the Philippines has steadily increased over recent years, with several reports estimating this increase to be 8 to $12 \%$ per annum. ${ }^{4,2}$ Of the 5.52 million registered motor vehicles in 2007, almost half (48\%) were motorized two- and threewheeled vehicles. ${ }^{3,5}$ In China, significant increases in the numbers of motorcycle owners coincided with substantial increases in the numbers of road traffic injuries involving motorcycle users. ${ }^{6}$

The Metropolitan Manila Development Authority (MMDA), the government agency in charge of traffic law enforcement in Metropolitan Manila (the country's center of economic activity), reported substantial increases in MCRT deaths (54\%) and injuries (29\%) from 2004 to $2005 .{ }^{3}$ These estimates apply to crashes occuring in Metro Manila only and are limited to pre-hospital deaths (at the scene) or injuries without attribution nor description of the in-hospital course of MCRT victims. 
As a first step to address the dearth of information relating to motorcycle crashes in a rapidly motorizing nation, this study describes the epidemiology of MCRT based on admissions to the Trauma Division of the National University Hospital of the Philippines, the University of the Philipines-Philipine General Hospital (PGH). The aims of the study are to describe the injuries of MCRT victims; the types of road users involved; identify populations at particular risk; and ascertain the extent to which MCRT victims in this setting were considered to have been riding under the influence of alcohol and not wearing helmets. Based on these findings, interventions that could reduce the burden of MCRT for those at highest risk are considered.

\section{Methods}

This study involved a retrospective review of the clinical records of all victims of motorcycle-related trauma (MCRT) admitted to the Trauma Division, Department of Surgery, Philippine General Hospital (PGH), for the 3-year period, January 1, 2004 to December 31, 2006. Only patients assessed by the trauma triage officer to have multiple injuries consistent with an Injury Severity Score of $\geq 9$ or those with severe unifocal injuries are admitted to the Trauma Division in the study hospital. Less severe injuries that did not warrant admission to the Trauma Division were not included in the electronic patient database that was analyzed in this study. Victims of MCRT with isolated neurologic or orthopedic injuries are not included in this review as they are seen and treated by other healthcare providers within PGH.

Data was extracted from the electronic patient records in the Integrated Surgical Information System (ISIS) of the PGH Department of Surgery. At the time the review was conducted, the ISIS was in its first years of use with data encoding and entry done by surgical interns and residents. A detailed description of the ISIS database and Philippine trauma systems is available elsewhere. ${ }^{7}$

MCRT was defined as "any injury to a road user resulting from a collision with a motorcycle, whether as a motorcycle driver, passenger, cyclist, pedestrian or other road user". The following search terms were used to ensure that all MCRT were included in this study: motor, cycle, motorcycle, motor cycle, motorbike, and motor bike. Data on the patient's age, gender, length of hospital stay, body part injured, nature of injury (e.g., fractures), in-hospital mortality, medical complications, and crash characteristics (e.g., involvement of other vehicles and structures) were systematically extracted for analysis using a standardized abstract form.

Data management and descriptive analyses were performed using Microsoft Office Excel 2007. Approval for medical record access, review and analysis was obtained from the Institutional Review Board of the University of the Philippines, Manila.

\section{Results}

A total of 310 patients admitted to the Trauma Division following MCRT from 2004-2006 met the study inclusion criteria; however, only $78 \%$ (241) had evaluable records. These comprised $6.7 \%$ of all trauma admissions to the Trauma Division, Department of Surgery, PGH. With 74, 112 and 124 patients meeting the study case definition over the three consecutive years, there was a $67 \%$ increase in serious MCRT admissions during the study period. No changes to the admission or trauma triage criteria occurred during this period.

As shown in Table 1, the majority of MCRT victims were young adults (mean 27.7 years, median 26 years; range 0-84 years); $83.8 \%$ were male. Almost two thirds of the road users involved in crashes involving motorcycles (MCRT victims) were motorcycle drivers or pillion riders $(\mathrm{N}=148$; $61.4 \%), 27 \%$ of whom were involved in single vehicle crashes. Importantly, $38.6 \%$ of MCRT victims in this study $(\mathrm{N}=93)$ were not motorcyclists, over half of whom were pedestrians (Table 1).

Of the 152 patient records which documented information on alcohol use, 134 victims $(88 \%)$ reported that they had consumed alcohol prior to the crash. Of the 84 records of injured motorcyclists documenting information on helmet use, only 11 (13\%) reported the rider was wearing a helmet at the time of the crash.

Two-thirds of MCRT victims suffered injuries to more than one body site. The maxillo-facial region was the most commonly affected site $(78 \%)$, followed by the lower extremity $(46.9 \%)$ and the brain $(40.7 \%)$. Maxillo-facial trauma, traumatic brain injuries, skull fractures, lower and upper extremity injuries and chest trauma were more common presentations among motorcyclists than other MCRT victims (Table 1).

Fourteen out of the 241 evaluated cases died during treatment translating to an in-hospital mortality rate of $5.8 \%$. Of these 14 deaths, six (43\%) had traumatic brain injuries (e.g., intracranial hemorrhage or brain herniation), four died of septic shock, and the remaining deaths were attributed to hemorrhagic shock, unrecognized upper airway obstruction and acute respiratory distress syndrome. In addition, a further 11 cases had admissions complicated by nosocomial pneumonia, fascial dehiscence, anastomotic leak, superficial surgical site infection, and myocardial infarction. It is noted, however, that the electronic patient database did not have a systematic approach to recording all potential complications during the admission or following discharge.

The average length of hospital stay was 16.7 days (median: 13 days; range 2 to 163 days). Only $4.4 \%$ of the patients were private (fee-for-service) patients with the remainder reliant on government-subsidized 'free' medical services. 
Table 1. Key Characteristics of motorcycle-related trauma (MCRT) victims admitted to the Philippine General Hospital: 20042006

\begin{tabular}{|c|c|c|c|c|c|c|}
\hline \multirow[t]{2}{*}{ Characteristic } & \multicolumn{2}{|c|}{ All MCRT victims } & \multicolumn{2}{|c|}{$\begin{array}{l}\text { Motorcyclist (driver/rider or } \\
\text { pillion passenger) }\end{array}$} & \multicolumn{2}{|c|}{$\begin{array}{l}\text { Road users other than motorcyclists* } \\
\text { (e.g., pedestrian, bicyclist) }\end{array}$} \\
\hline & $\mathrm{n}=\mathbf{2 4 1}$ & $\%$ & $\mathrm{n}=148(61.4 \%)$ & $\%$ & $n=93(38.6 \%)$ & $\%$ \\
\hline Median age (years) & 26 & & 26 & & 25 & \\
\hline Mean Length of stay (days) & 16.7 & & 29 & 19.4 & & 12.7 \\
\hline Males & 202 & $83.8 \%$ & 124 & $83.8 \%$ & 78 & $83.9 \%$ \\
\hline In-hospital mortality & 14 & $5.8 \%$ & 9 & $6.1 \%$ & 3 & $3.2 \%$ \\
\hline \multicolumn{7}{|l|}{ Injuries sustained (site) } \\
\hline Multiple injuries & 166 & 68.9 & 132 & 89.2 & 34 & 36.6 \\
\hline Maxillo-facial trauma & 188 & 78 & 134 & 90.5 & 54 & 58.1 \\
\hline Traumatic brain injury & 98 & 40.7 & 76 & 51.4 & 22 & 23.7 \\
\hline Skull Fracture & 92 & 38.2 & 67 & 45.3 & 25 & 26.9 \\
\hline Lower Extremity injuries & 113 & 46.9 & 93 & 62.8 & 20 & 21.5 \\
\hline Upper Extremity injuries & 87 & 36.1 & 85 & 57.4 & 2 & 2.2 \\
\hline Chest injuries & 39 & 16.2 & 33 & 22.3 & 6 & 6.5 \\
\hline Abdominal injuries & 31 & 12.9 & 20 & 13.5 & 11 & 11.8 \\
\hline
\end{tabular}

\section{Discussion}

To our knowledge, this is the first report describing the characteristics of severely injured MCRT victims necessitating hospital admission in the Philippines. Based on admissions to a major trauma center, the average MCRT victim in the Philippines is a young adult male, does not wear a motorcyle helmet, and is highly likely to have driven under the influence of alcohol. Maxillo-facial and traumatic brain injuries were the most common injuries recorded in this study population. The average length of stay in hospital was about 2 weeks, and one in twenty died or suffered a major complication during the admission. Almost $40 \%$ of those injured in these crashes were not riding motorcycles themselves.

When interpreting the findings, several limitations of this study need to be considered. The selection criteria that influence hospital admission and trauma team activation at the Philippine General Hospital, these findings do not represent the population burden of MCRT, particularly victims who died at the roadside or prior to hospital admission, experienced difficulties getting access to hospital care, sustained isolated orthopedic, neurologic and thermal injuries, or sustained injuries that were deemed minor. It is acknowledged that while the latter may not pose a major threat to life, they could impart long-term disability.

As this is a retrospective review of clinical records, the data elements were not collected solely or systematically for the purposes of the study. Consequently, these lack the level of detail and completeness that would have been ideal. In particular, 1 in 5 patient records could not be accessed or fully evaluated, and missing information was a common occurrence when considering data on alcohol use (lacking in $37 \%$ of all victims) and helmet use (lacking in $43 \%$ of all motorcyclist victims). Furthermore, there were several limitations to the types of information captured in the database. For example, it was not possible to attribute alcohol involvement to specific road users, provide an accurate profile of all potential in-patient (or post-discharge) complications, quantify their in-hospital costs and provide pertinent details regarding patients' long term outcomes.

Further efforts and resources are required to improve the quality of the data and support the access to and dissemination of this information in a timely manner to inform road safety efforts.

Notwithstanding these limitations, the findings of this study provide useful insights that are particularly pertinent to the Philippine Road Safety Action Plan which was released in January 2004 as a collaborative effort of the Departments of Education, Health, Interior and Local Government, Public Works and Highways, Trade and Communication and the Philippine National Police-Traffic Management Group. This 5-year plan was intended to have an immediate and long-term impact on the safety of the most vulnerable road users in the country, particularly pedestrians and motorcyclists. ${ }^{8}$ This multi-sectoral strategy recognized the need to inform senior decision makers about the need to prioritize and adequately resource specific interventions that could address the problem of road crashes.

More than $75 \%$ of the MCRT victims were in the $15-44$ year old age group which comprises only $50 \%$ of the general population. Only $13 \%$ of the motorcyclist victims were wearing helmets during the crash, an estimate much lower than the national rate of $34 \%$ published in the Global Status Report on Road Safety. ${ }^{5}$ As reported in the latter, the Philippines did not have a national helmet law nor an established helmet standard during the study period. Studies in numerous settings have demonstrated reductions in deaths from head injury among MCRT victims following the implementation of laws that mandate helmet use when 
riding motorcycles as well as helmet standards..$^{2,9-12}$ Implementing and enforcing similar laws in the Philippines will be particularly important given the significant burden of traumatic brain injury, a cause of $43 \%$ of all MCRT deaths in this study.

Where information was documented in clinical records, the vast majority of MCRT victims (88\%) had reported using alcohol prior to their crash. Objective measures of alcohol were unavailable as breathalyzer or blood alcohol concentration testing of road crash victims is rarely done in the Philippines. While self-reports are expected to underestimate the prevalence of alcohol use prior to a crash, secondary gains from denying alcohol intake were less likely to have been a major issue in the Philippines as there was no law against drink-driving during the study period, and medical insurance was not withheld for "driving under the influence". There are no previous published reports on alcohol use and its contribution to MCRT in the Philippines. Of the countries in the Western Pacific region included in the WHO Global Status Report on Road Safety, the Philippines was the only country without drink-driving legislation, revealing an important but neglected aspect of MCRT prevention. ${ }^{5}$

Importantly, this study also highlights the impact of MCRT on vulnerable road users other than motorcyclists, particularly pedestrians. In surveys conducted in five cities by SAFE KIDS Philippines, over $36 \%$ of 9,975 schoolchildren aged 10 to 11 years responded that they had been hit by a vehicle while walking to and/or from school. More than $80 \%$ were hit by two- and three-wheeled vehicles ( $46 \%$ bicycles, $13 \%$ pedicabs, $12 \%$ tricycles and $14 \%$ motorcycles). ${ }^{13}$ While most of these injuries did not pose a significant threat to life, the risk of longer term physical disability or psychiatric trauma cannot be discounted. ${ }^{14}$ An ER survey in three Philippine cities found that pedestrian injuries accounted for $28 \%$ of emergency room presentations by children, $70 \%$ of whom had been struck by a two- or three-wheeled vehicle (18\% motorcycle, $23 \%$ tricycle [motorcycle with a covered sidecar used as a public utility vehicle] and 29\% bicycle). ${ }^{15}$

While these data underestimate the impact of MCRT in many dimensions, particularly for impoverished victims, their families and communities, the healthcare costs for the relatively lengthy hospitalisations impose a substantial burden on the public health system. ${ }^{16}$ The complicated care of multisystem, neurosurgical and orthopedic injuries contributes to the relatively long periods of hospitalisation and increasing costs due to MCRT. ${ }^{10,15}$

\section{Conclusions}

Motorcycle-related trauma imposes a major burden on the most economically productive but socio-economically disadvantaged segment of the Philippine population. The preponderance of maxillo-facial injuries and traumatic brain injuries among those admitted to trauma centers and the high proportion of injured motorcyclists who were riding under the influence of alcohol, or involved in single vehicle crashes, underscore the need to ensure the use of standardized helmets and that national drink driving laws are legislated and enforced. Injury prevention and control efforts must also address issues of particular relevance to non-motorcycle users who comprise a significant proportion of victims of MCRT in the Philippines.

\section{Acknowledgments}

The completion and presentation/s of this study were supported by a Senior Researcher Grant from the Road Traffic Injuries Research Network (RTIRN), funded by the World Bank Global Road Safety Facility, and the Mu Sigma Phi Foundation Inc., College of Medicine, University of the Philippines, Manila.

\section{References}

1. Peden M, Scurfield R, Sleet D, et al. World report on road traffic injury prevention. Geneva. World Health Organization. 2004.

2. Ross A, Melhuish C. Road safety in ASEAN: introducing a regional approach. Manila, Philippines: Transport and Communications Bulletin for Asia and the Pacific. No. 74, 2005.

3. Metro Manila Accident Reporting and Analysis System. Annual Report January-December 2006. (MP 9-11/13). Manila: Metro Manila Development Authority. 2006. pp 9-11.

4. Motorcycles and Tricycles in the Philippines [Online]. [cited 2007 March]. Available from http://www.philippines.hvu.nl/transport3.htm.

5. Global status report on road safety: time for action. Geneva, World Health Organization [Online]. 2009 [cited 2011 April]. Available from www.who.int/violence_injury_prevention/road_safety_status/2009.

6. Zhang J, Norton R, Tang KC, Lo SK, Jiatong Z, Wenkui G. Motorcycle ownership and injury in China. Inj Control Saf Promot. 2004; 11(3):159-63.

7. Consunji RJ, Serrato Marinas JP, Aspuria Maddumba JR, Dela Paz DA Jr. A profile of deaths among trauma patients in a university hospital: The Philippine experience. J Inj Violence Res. 2011; 3(2):85-9.

8. Philippine Road Safety Action Plan. Department of Transportation and Communications, Department of Public Works and Highways, Department of Health, Department of Interior and Local Government, Philippine National Police, Department of Education, University of the Philippines National Center for Transportation Studies. Assisted by the ADB/ASEAN Regional Road Safety Project. January 2004.

9. Hyder AA, Waters H, Phillips T, Rehwinkel J. Exploring the economics of motorcycle helmet laws-implications for low and middle-income countries. Asia Pac J Public Health. 2007; 19(2):16-22.

10. Liu B, Ivers R, Norton R, Blows S, Lo SK. Helmets for preventing injury in motorcycle riders. Cochrane Database Syst Rev. 2004; (2):CD004333.

11. Chiu WT, Kuo CY, Hung CC, Chen M. The effect of the Taiwan motorcycle helmet use law on head injuries. Am J Public Health. 2000; 90(5):793-6.

12. Tham KY, Seow E, Lau G. Pattern of injuries in helmeted motorcyclists in Singapore. Emerg Med J. 2004; 21(4):478-82.

13. Rolloque AC, Perez MTA, Alcantara MM, Rolloque J, Consunji RJ. School zone pedestrian safety assessments using the Walk This Way of Safe Kids Philippines. Poster presented at the $9^{\text {th }}$ World Conference on Injury Prevention and Safety Promotion. Merida, Mexico. March 15-18 2008.

14. Ouellet J, Kasantikul V. The Effect of Blood Alcohol Concentration on Motorcycle Crash Characteristics [Online]. 2001 [cited 2008 March]. Available from $\quad$ www.msf-usa.org/imsc/proceedings/ dOuelletEffectofBAConMotorcycleCrashCharacteristics.pdf .

15. Consunji RJ, Alcantara M, Orlando O, Rolloque A, Perez MT. The Epidemiology of Emergency Room Consults for Injuries in Filipino Children. Poster presented at the $9^{\text {th }}$ World Conference on Injury Prevention and Safety Promotion. Merida, Mexico. March 15-18 2008.

16. Crisostomo A, Paz-Arcilla C, Arcilla E. A survey of general surgery operations from 1991-1993: defining the scope of general surgery in the Philippines. Phillip J Surg Spec. 1995; 50(1):29-35. 